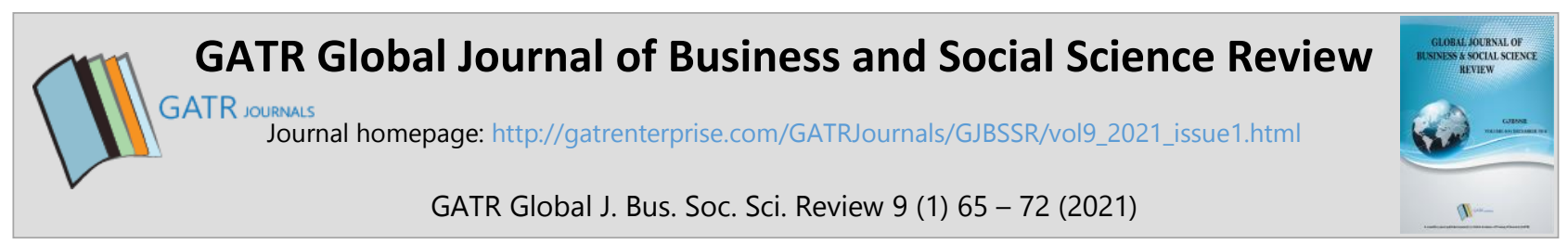

\title{
Purchase Behaviour of Environment-Friendly Automobiles
}

\author{
Anesu M. Mabaire ${ }^{*}$, XU Guangquan², Ngqabutho Moyo ${ }^{3}$ \\ ${ }^{1,2}$ School of Earth and Environment, Anhui University of Science and Technology, Huainan, China \\ ${ }^{3} \mathrm{NM}$ Professional Consultants, Pretoria, South Africa
}

\begin{abstract}
Objective - This research seeks to examine the purchase behaviour of environment-friendly automobiles. It also identifies the key factors affecting the purchase intention of green vehicles. The study adopted a quantitative approach, and primary data was analysed on Smart PLS3. The researcher utilised a non-probability sampling technique to select the most appropriate sample for this study. This type of sampling is also known as purposive sampling, deliberate sampling, and or judgement sampling. Independent variables of this study include environmental attitudes such as; environmental knowledge, environmental values and responsibility feeling. These variables were tested against purchase intention, which is regarded as a dependent construct of this study.

Finding - Based on the findings, all the proposed hypotheses of this study are proven significant. Environmental knowledge has a positive effect on environmental values. Environmental values have a significant effect on the formation of a responsibility feeling. Responsibility feeling has a significant effect on the purchase intention of green vehicles.

Novelty - Individuals who possess adequate knowledge about their environment are likely to develop environmental values, which then transforms into a responsibility feeling towards the environment and then predict the purchase intention of environment-friendly automobiles. Citizens should thus be equipped with adequate knowledge about environmental issues, through formal and informal education, and through socialization agencies and awareness campaigns, as this will help in boosting pro-environmental and sustainable human behaviours.
\end{abstract}

Type of Paper: Empirical.

JEL Classification: O31, O32, O33.

Keywords: Environment-friendly automobiles; purchase intention; environmental knowledge; environmental values; responsibility feeling.

Reference to this paper should be made as follows: Mabaire, A.M; Guangquan, X.U; Moyo, N. (2021). Purchase Behaviour of Environment-Friendly Automobiles, GATR Global J. Bus. Soc. Sci. Review, 9(1): 65 - 72. https://doi.org/10.35609/gjbssr.2021.9.1(8)

\section{Introduction}

The issue of environmental pollution has attracted the attention of several researchers and a wide range of organisations around the world (Moyo and Masuku, 2018). It has long been of the major concern among the current generation (Yusof et al, 2013).

\footnotetext{
* Paper Info: Revised: December 24, 2020

Accepted: March 31, 2021

* Corresponding author: Anesu M. Mabaire

E-mail: anesumunyaradzi02@gmail.com

Affiliation: School of Earth and Environment, Anhui University of Science and Technology, China
} 
As such, research on environmental issues has gained a wide space in business and academia. The common challenges that have been widely reported include; the ecosystem breakdown, climate change, acid rains, as well as harmful waste secretions (Lou, Wang and Yang 2017). Transportation industry is regarded as one of the top leading contributors of carbon dioxide emissions (IEA World Energy Outlook, 2006). Du and Ouyang (2016) stipulated that China is experiencing an increase in air pollution as a result of the rapid expansion in vehicle ownership among the citizens. The commonly used vehicles are relying on petrol and diesel combustion engines, which are mainly associated with the poisonous gas emissions such as carbon dioxide (Schulte, Hart and van der Vost, 2004). Environmental concern has created a trend of eco-friendly consumption known as the green consumerism, which has also influenced the development of sustainable communities (Yusof et al, 2013). Today, many consumers are willing to purchase green products in order to sustain their environment.

To protect the environment, the government of China is encouraging the adoption of green vehicles (Moyo and Masuku, 2018). Green vehicles include automobiles such as the electric vehicles that use the battery and the hybrid plug-in electric vehicles (Thomas, 2012). Environmentally friendly automobiles are becoming dominant in both developed and developing automobile markets (Ustaoglu and Yildiz, 2012; Brown, Pyke and Steenhof, 2010). The introduction of electric vehicles plays a pivotal role in the reduction of poisonous gas emissions (Buekers et al, 2014; Poullikkas, 2015; Lesemann, Welfers and Eckstein, 2012; Onat, Kucukvar, Aboushaqrah and Jabbar, 2019; Williams, Das and Fisher, 2020; Lou et al, 2017; Du and Ouyang, 2016).

The adoption of environment-friendly automobiles has sparked an interesting field of research in business and academia. Various researchers such as Lou et al (2017), Rezvani, Jansson and Bodin, (2015), and Moyo and Masuku (2018) have discussed key issues surrounding green transportation. However, little attention has been drawn towards studying the factors and attitudes influencing the adoption of environment-friendly automobiles in the Southern part of China. Research on consumer perceptions regarding green vehicle adoption has not yet been fully explored. Instead, several scholars have mainly focused on issues such as environmental laws and policies, and the technological innovations within the area of sustainability. Therefore, this research seeks to cover this gap through examining the effect of environmental attitudes such as; environmental knowledge, environmental values and responsibility feeling on the intention to purchase environment-friendly automobiles. As such, environmental knowledge, environmental values and responsibility feeling are treated as independent variables of this study, while purchase intention is regarded as a dependent variable representing the actual purchase behaviour.

To the already existing literature, this study is contributing in the following ways: Firstly, it seeks to identify and explain the key factors influencing the purchase intention of environment-friendly automobiles. These factors include; environmental knowledge, environmental values and the responsibility feeling. Secondly, this study is stretching the need for the citizens to acquire environmental knowledge, since individuals who have adequate knowledge about their environment are highly likely to possess environmental values, which then transforms into a responsibility feeling towards the environment and thereby predicting the purchase intention of green vehicles.

The remaining part of the paper is organised as follows: Section 2 is made up of the literature review of this study. It encompasses a detailed discussion of the key variables of this study and the development of the proposed hypotheses. Section 3 is focusing on the research methodology of this study. It consists of the research approach, type of data, sampling techniques, research instruments and the research design. The results of this study are presented in Section 4, and then discussed in Section 5. Section 6 concludes the paper.

\section{Literature Review}

The research on the adoption of environment-friendly automobiles has gained momentum over the past few years. Electric vehicles (EVs) are being introduced widely as a way of solving the problem of depending

GATR Global J. Bus. Soc. Sci. Review 9 (1) 65 - 72 (2021) 
on fossil fuels, the increasing rate of carbon dioxide (CO2) emissions, and other environmental challenges (Rezvani, et al, 2015:122). "EVs include vehicles with different technologies such as plug-in hybrid electric vehicles (PHEVs), extended-range battery electric vehicles (E-REVs), battery electric vehicles (BEVs) and hybrid electric vehicles (HEVs)" (Rezvani, Jansson and Bodin, 2015:123). As part of taking action on climate change, many governments are advocating for the adoption and use of EVs. In order to effectively promote the adoption of environment-friendly automobiles, there is need to understand the manner in which consumers perceive environment-friendly automobiles and to identify the possible drivers for and barriers against the adoption of these types of vehicles (Rezvani et al, 2015). In other words, it is of paramount importance to understand the key factors influencing the purchase intention of environment-friendly automobiles.

Various theories have been developed and used to explain the adoption behaviour of environment-friendly automobiles. Ajzen's (1991) theory of planned behaviour entails that people's decisions are based on the rational assessments of the stimuli or influence and the possible ramifications of those decisions. In this regard, consumers are fully aware of the outcome and the consequences of purchasing an environmentally friendly automobile. The theory suggests that if a consumer perceives that a behavior is normal in the society, he or she is likely to perform the behavior.

Bamberg and Moser (2007) articulates that consumer attitude is a predictor of intentions, meaning that by looking at a consumer's attitude towards an environmentally friendly automobile, one can tell their intention to purchase. Subjective social norms have also been identified by Moons and De Pelsmacker (2012) as factors that also affect consumer's attitude towards adopting environmentally friendly automobiles, and these include; expectations from the society, that is; willing to be identified with a certain class in a society, peers' ideas about environment-friendly automobiles and affordability.

Kaiser, Ranney, Hartig and Bowler's (1999) theory of ecological behaviour as a function of environmental attitude constitutes valuable constructs such as environmental knowledge, responsibility feeling and environmental values which are vital in the prediction of a pro-environmental behaviour, such as the adoption of environment-friendly automobiles. Kaiser et al' (1999) model entails that; environmental knowledge, responsibility feeling and environmental values should be used in the prediction of ecological behaviour (Henning and Karlsson, 2011).

Environmental knowledge can be defined as the common awareness of the essential facts, relationships and concepts which relates to the natural environment and the entire ecosystem at large (Fryxell and Lo, 2003:45). It is also elucidated as that deep understanding which people or citizens possess about their environment and the surrounding (Yusof et al, 2013). Environmental knowledge is of paramount importance in ensuring environmental sustainability and conservation (Latif et al, 2013). The knowledge that people have about their environment is regarded as a prerequisite of environmental attitude (Henning and Karlsson, 2011; in Yusof et al, 2013). Environmental knowledge is very essential in reinforcing environmental values amount societal members. A model by Kaiser et al (1999) indicates how critical the role played by environmental knowledge is in influencing ecological behavior. Therefore, the significance of environmental knowledge cannot be underestimated. As such, hypothesis 1 was developed:

\section{Hypothesis 1: Environmental knowledge has a positive effect on environmental values.}

Environmental values are concerned with the importance that people attach towards their environment which may then lead them to want to consume products that will protect and not harm their environment as a sign of being responsible citizens. Consumers have a tendency of depending on environmental values in predicting ecological behaviour, meaning that values can influence how consumers can take care of their environment (Kaiser et al, 1999). The care and value they give to their environment will motivate them to act responsibly and adopt environmentally friendly products (Moyo and Masuku, 2018). Hypothesis 2 was thus crafted: 


\section{Hypothesis 2: Environmental values has a positive effect on the responsibility feeling}

According to Yusof et al (2013), many consumers would prefer to purchase products which protect their environment. Some consumers have made it their responsibility to protect their environment through the purchase and use of environment-friendly automobiles (Moyo and Masuku, 2018). Kaiser et al (1999) entails that a consumer's responsibility feeling influences the purchase decision of environmentally friendly products, meaning that a consumer can choose to buy an environmentally friendly automobile simply because he or she cares about his or her environment and feels responsible for protecting it. Hypothesis 3 was then developed:

\section{Hypothesis 3: Responsibility feeling has a positive effect on the purchase intention of environment- friendly automobiles}

\section{Research Methodology}

The researcher made use of a quantitative approach on a targeted population of 872 adults from the Southern part of China. This research utilised non-probability sampling, on the bases that it "does not afford any basis for estimating the probability that each item in the population has of being included in the sample" (Kothari, 2004:59). Non-probability sampling is also known as purposive sampling, deliberate sampling, and judgement sampling (Kothari, 2004). Under non-probability sampling, the items for the chosen sample are deliberately selected by the researcher; based on his or her supreme choice (Kothari, 2004). The researcher also relied on primary data which was gathered through a questionnaire survey. Based on the objectives of this research, and the developed measurement constructs of this study, a questionnaire survey was crafted and then tested. It was then distributed to the targeted respondents.

Data collection was carried out within a space of six months, in the Southern part of China. Out of 198 survey questionnaires that were sent, the respondents returned 189 which were all regarded as valid. The researcher also carried out the process of data cleaning and screening in order to eliminate unnecessary errors during the stage of data analysis. To enter and record data, the researcher used a Statistical Package for Social Sciences (SPSS Version 20). Data analysis was then conducted on Smart PLS3, and it involved testing items of the measurement constructs of this study for reliability and validity. The constructs include; environmental knowledge, environmental values, responsibility feeling and purchase intention. Variables of this study are measured on a Likert scale that ranges from; (1) strongly disagree to; (5) strongly agree. The measurement items of this study are adapted from Henning and Karlsson (2011).

\section{Results}

This research seeks to test the impact of environmental knowledge on environmental values. It also determines the strength of environmental values on responsibility feeling and then examines the effect of the responsibility feeling on the purchase intention of green automobiles. Out of 189 respondents, 87 (46\%) were males while $102(54 \%)$ were females. With regards to the age of respondents, $23(12.2 \%)$ were aged below 21 years, while $99(52.4 \%)$ were in the age category of 21 to 30 years. In addition, $41(21.7 \%)$ respondents were aged between 31 and 40 years, whereas $26(13.8 \%)$ were falling under the age category of 41 to 50 years. In terms of the highest level of education attained, $24(12.7 \%)$ respondents had completed the high school level, while 43 (22.8) had attained their diplomas. Moreover, 119 (63\%) respondents had completed their bachelor's degrees, while the remaining $3(1.6 \%)$ were in possession of master's degrees. Hence all the respondents had attained a certain level of education.

The results of hypotheses testing from Smart PLS3 indicate that all the constructs of this study are proven significant, but with different strengths. Figure 2 shows the results of the PLS Algorithm, whereas figure 3 
illustrates the results of bootstrapping. As shown in figure 2, validity and reliability analysis were conducted, and the results came out positive.

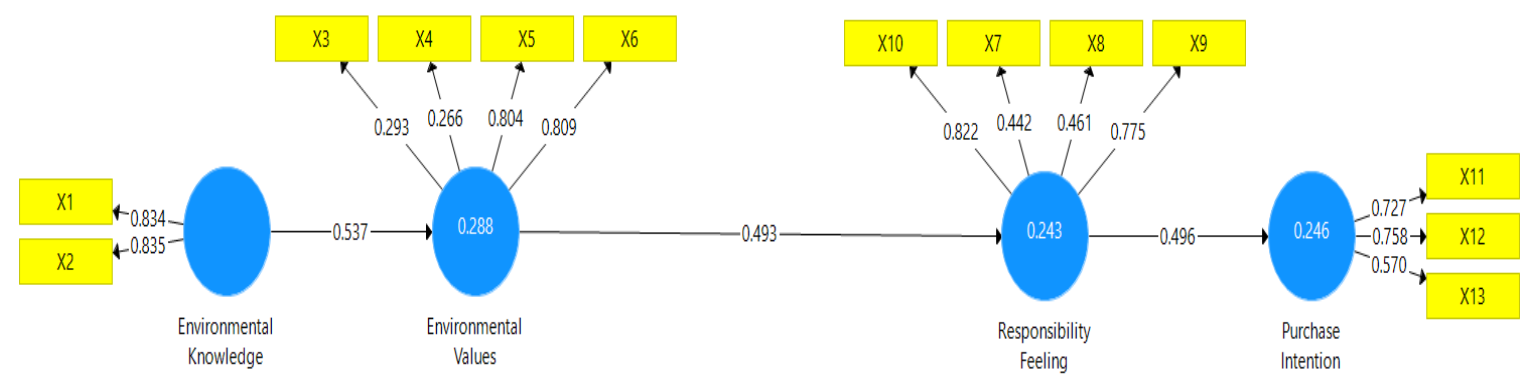

Figure 2. Results of PLS Algorithm

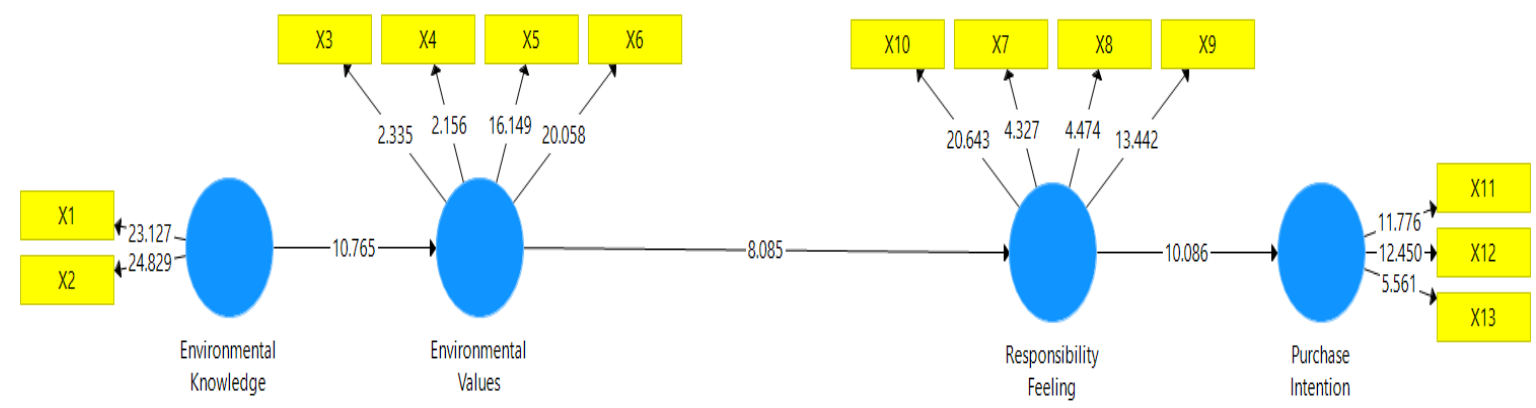

Figure 3. Results of bootstrapping

As highlighted in figure 3, bootstrapping results shows that environmental knowledge has a positive effect on environmental values, with strength of 10.765 . The strength of environmental values on responsibility feeling is 8.085 , hence indicating a positive relationship between environmental values and responsibility feeling. The strength of responsibility feeling on purchase intention is 10.086 . Hence, there is a positive relationship between responsibility feeling and purchase intention.

Table 1. Results of Hypotheses Testing

\begin{tabular}{|c|c|c|c|}
\hline Hypothesize Effect & T - Statistics & P - Values & Results \\
\hline $\begin{array}{c}\text { Hypothesis 1: Environmental knowledge has a positive } \\
\text { effect on environmental values. }\end{array}$ & 10.765 & 0.000 & Positive \\
\hline $\begin{array}{c}\text { Hypothesis 2: Environmental values have a positive effect } \\
\text { on responsibility feeling. }\end{array}$ & 8.085 & 0.000 & Positive \\
\hline $\begin{array}{c}\text { Hypothesis 3: Responsibility feeling has a positive effect } \\
\text { on purchase intention. }\end{array}$ & 10.086 & 0.000 & Positive \\
\hline
\end{tabular}

Having obtained: $\mathrm{t}$-statistics $=10.765$ and $\mathrm{p}-$ value $=0.000$, environmental knowledge has a significant effect on environmental values. As shown in table 1 , environmental values have a significant effect on responsibility feeling: $\mathrm{t}-$ statistics $=8.085$ and $\mathrm{p}-$ value $=0.000$. With: $\mathrm{t}-$ statistics $=10.086$ and $\mathrm{p}-$ value $=0.000$, responsibility feeling has a positive effect on purchase intention. As such, the findings of this study are indicating that the intention to purchase environment-friendly automobiles is influenced by environmental attitudes such as environmental knowledge, environmental values and responsibility feeling. 


\section{Discussion}

Environmental knowledge is a key driver of pro-environmental behavior among societal members. Kollumuss and Agyeman (2002) define pro-environmental behavior as that behavior which strives by all means to deliberately reduce negative impacts of ones actions towards the environment. Saripah et al (2013) stipulate that environmental knowledge ought to be imparted in people by means of environmental education which should be rooted in syllabuses at school so that knowledge about environmental wellbeing and its values is cultivated and spread among citizens from as young as preschool level.

A research that was carried out by Henning and Karlsson (2011) and Yusof et al (2013) indicates that environmental values influences people to act responsibly towards their environment. Environmental values are a key source of a pro-environmental behaviour among societal members.

Moyo (2018) points out that those consumers who possess environmental concern are willing to purchase environmentally friendly automobiles because of their technology that promotes environmental protection and sustainability. Kim and Damhot (1998) reveal that consumers with responsible feeling for their environment will buy green products in order to protect their environment from air pollution.

\section{Conclusion}

This study examined the purchase behaviour of environment-friendly automobiles in the Southern part of China. Based on the results of this study, environmental knowledge, environmental values and responsibility feeling are very essential in predicting the behaviour of the adoption of environment-friendly automobiles. Environmental knowledge has a significant effect on the establishment of environmental values. Environmental values have a significant effect on the formation of a responsibility feeling. A responsibility feeling has a significant effect on the purchase intention or decision of environment-friendly automobiles. The study implies that, individuals who possess adequate knowledge about their environment are highly likely to develop environmental values, which then transforms into responsibility feeling towards the environment. As such, governments should ensure that their citizens are equipped with adequate knowledge on environmental issues, through formal and informal education, and through socialization agencies and awareness campaigns, as this will help in boosting pro-environmental and sustainable human behaviours and thereby creating responsible citizens. The current study did not account for the financial benefits and costs of using environment-friendly automobiles. Hence, future researchers should seek to advise consumers on this subject matter. Addressing this issue will also benefit the policy makers and all the marketing specialists. In addition, this research did not dwell much on the key polices influencing the adoption of green vehicles. Hence, future researchers should seek to examine the effect of policies on the adoption behaviour of environment-friendly automobiles.

\section{References}

Ajzen, I. (1991). The theory of planned behavior. Organizational behavior and human decision processes, 50(2), 179211. http://doi.org/10.1016/0749-5978(91)90020-T

Bamberg, S., \& Möser, G. (2007). Twenty years after Hines, Hungerford, and Tomera: A new meta-analysis of psychosocial determinants of pro-environmental behaviour. Journal of environmental psychology, 27(1), 14-25. https://doi.org/10.1016/j.jenvp.2006.12.002

Brown, S., Pyke, D., \& Steenhof, P. (2010). Electric vehicles: The role and importance of standards in an emerging market. Energy Policy, 38(7), 3797-3806. https://doi.org/10.1016/j.enpol.2010.02.059

Buekers, J., Van Holderbeke, M., Bierkens, J., \& Panis, L. I. (2014). Health and environmental benefits related to electric vehicle introduction in EU countries. Transportation Research Part D: Transport and Environment, 33, 2638.https://doi.org/10.1016/j.trd.2014.09.002

Du, J., \& Ouyang, D. (2017). Progress of Chinese electric vehicles industrialization in 2015: A review. Applied Energy, 188, 529-546.https://doi.org/10.1016/j.apenergy.2016.11.129 
Fryxell, G. E., \& Lo, C. W. (2003). The influence of environmental knowledge and values on managerial behaviours on behalf of the environment: An empirical examination of managers in China. Journal of business ethics, 46(1), 45-69. http://doi.org/10.1023/A:1024773012398

Henning, O., \& Karlsson, S. (2011). Environmental attitudes and how they affect purchase intentions of environmentally friendly automobiles: An emperical study on Chinese students at Jönköping University.

Yusof, J. M., Singh, G. K. B., \& Razak, R. A. (2013). Purchase intention of environment-friendly automobile. ProcediaSocial and Behavioral Sciences, 85, 400-410.https://doi.org/10.1016/j.sbspro.2013.08.369

IEA World Energy Outlook. (2006). International Energy Agency: Paris, France. https://doi.org/10.1787/weo2006-en

Kaiser, F. G., Ranney, M., Hartig, T., \& Bowler, P. A. (1999). Ecological behavior, environmental attitude, and feelings of responsibility for the environment. European psychologist, 4(2), 59. http://doi.org/10.1027//1016-9040.4.2.59

Kim, H. S., \& Damhorst, M. L. (1998). Environmental concern and apparel consumption. Clothing and Textiles Research Journal, 16(3), 126-133.https://doi.org/10.1177\%2F0887302X9801600303

Kollmuss, A., \& Agyeman, J. (2002). Mind the gap: why do people act environmentally and what are the barriers to pro-environmental behavior? Environmental education research, 8(3), 239-260. https://doi.org/10.1080/13504620220145401

Latif, S. A., Omar, M. S., Bidin, Y. H., \& Awang, Z. (2018). Analyzing the effect of situational factor on recycling behaviour in determining the quality of life. Journal of Asian Behavioural Studies, 3(6), 11-17. http://doi.org/10.21834/jabs.v3i6.231

Lesemann, M., Welfers, T., \& Eckstein, L. (2012). Development of a Fully Electric Light Duty Vehicle-The DELIVER Project. Procedia-Social and Behavioral Sciences, 48, 553-569. https://doi.org/10.1016/j.sbspro.2012.06.1034

Lou, Y., Wang, W., \& Yang, X. (2017). Customers' attitude on new energy vehicles' policies and policy impact on customers' purchase intention. Energy Procedia, 105, 2187-2193.https://doi.org/10.1016/j.egypro.2017.03.617

Moons, I., \& De Pelsmacker, P. (2012). Emotions as determinants of electric car usage intention. Journal of Marketing Management, 28(3-4), 195-237. http://doi.org/10.1080/0267257X.2012.659007

Moyo, N., \& Masuku, F. (2018). Based on Environmental Education: The Effects of Environmental Knowledge and Awareness on the Purchase Intention of New Energy Vehicles in the Southern part of China. Advances in Social Sciences Research Journal, 5(11) 390- 402. https://doi.org/10.14738/assrj.511.5405

Onat, N. C., Kucukvar, M., Aboushaqrah, N. N., \& Jabbar, R. (2019). How sustainable is electric mobility? A comprehensive sustainability assessment approach for the case of Qatar. Applied Energy, 250, 461-477. https://doi.org/10.1016/j.apenergy.2019.05.076

Poullikkas, A. (2015). Sustainable options for electric vehicle technologies. Renewable and Sustainable Energy Reviews, 41, 1277-1287.https://doi.org/10.1016/j.rser.2014.09.016

Rezvani, Z., Jansson, J., \& Bodin, J. (2015). Advances in consumer electric vehicle adoption research: A review and research agenda. Transportation research part $\mathrm{D}$ : transport and environment, 34, 122-136. https://doi.org/10.1016/j.trd.2014.10.010

Rogers, E. M., (2003).Diffusion of Innovations fifth Ed Free Press. New York. In Rezvani, Z., Jansson, J. \& Bodin, J. (2015). Advances in consumer electric vehicle adoption research: A review and research agenda. Transport Research Part D, 34, 122-136. https://doi.org/10.1016/j.trd.2014.10.010

Latif, S. A., Bidin, Y. H., \& Awang, Z. (2013). Towards the Realization of Green Cities: The moderating role of the residents' education level. Procedia-Social and Behavioral Sciences, 85, 646-652. https://doi.org/10.1016/j.sbspro.2013.08.392

Schulte, I., Hart, D., \& Van der Vorst, R. (2004). Issues affecting the acceptance of hydrogen fuel. International Journal of Hydrogen Energy, 29(7), 677-685. http://doi.org/10.1016/j.ijhydene.2003.09.006

Sovacool, B. K. (2009). Rejecting renewables: The socio-technical impediments to renewable electricity in the United States. Energy Policy, 37(11), 4500-4513.https://doi.org/10.1016/j.enpol.2009.05.073

Steg, L., \& Vlek, C. (2009). Encouraging pro-environmental behaviour: An integrative review and research agenda. Journal of environmental psychology, 29(3), 309-317. https://doi.org/10.1016/j.jenvp.2008.10.004

Stern, Paul C. "New environmental theories: toward a coherent theory of environmentally significant behavior." Journal of social issues 56.3 (2000): 407-424. https://doi.org/10.1111/0022-4537.00175

Rezvani, Z., Jansson, J., \& Bodin, J. (2015). Advances in consumer electric vehicle adoption research: A review and research agenda. Transportation research part D: transport and environment, 34, 122-136. https://doi.org/10.1016/j.trd.2014.10.010 
Thomas, C. S. (2012). How green are electric vehicles?. International journal of hydrogen energy, 37(7), 6053-6062. https://doi.org/10.1016/j.ijhydene.2011.12.118

Ustaoğlu, M., \& Yıldız, B. (2012). Innovative Green TechnologyinTurkey: Electric Vehicles' Future and Forecasting Market Share. Procedia-Social and Behavioral Sciences, 41, 139-146. https://doi.org/10.1016/j.sbspro.2012.04.018

Williams, E., Das, V., \& Fisher, A. (2020). Assessing the Sustainability Implications of Autonomous Vehicles: Recommendations for Research Community Practice. Sustainability, 12(5), 1902.https://doi.org/10.3390/su12051902

Yusof, J. M., Singh, G. K. B., \& Razak, R. A. (2013). Purchase intention of environment-friendly automobile. ProcediaSocial and Behavioral Sciences, 85, 400-410. https://doi.org/10.1016/j.sbspro.2013.08.369

\section{APPENDIX}

\section{MEASUREMENT ITEMS}

1: Excessive carbon dioxide emissions often lead to environmental pollution.

2: Driving an environment-friendly automobile reduces carbon dioxide emissions.

3: My environment is worth preserving.

4: I care about my environment.

5: Future generations should have access to a healthy environment.

6: Issues concerning environmental protection should be taken serious.

7: Driving an environment-friendly automobile would help protect my environment from air pollution.

8: I am personally responsible for advising my friends to consider adopting environmentally friendly automobiles so as to protect the environment.

9: I am personally responsible for leaving the earth in good shape for the benefit of the future generations.

10: I am personally responsible for reporting any negligent behaviour towards the environment to the responsible authorities.

11: I would buy an environmentally friendly automobile even if its price is higher than that of a regular car.

12: I would buy an environmental friendly automobile even if its performance is lower than that of a regular car.

13: I would buy an environmental friendly automobile even if it is less comfortable than a regular vehicle.

\section{Anesu M. MABAIRE}

ORCID: https://orcid.org/0000-0002-4204-7689

\section{Xu GUANGQUAN}

ORCID: https://orcid.org/0000-0002-2745-1579

\section{Ngqabutho MOYO}

ORCID: https://orcid.org/0000-0002-0140-9225 